\title{
, \\ Maternal Amino Acid Status in Severe Preeclampsia: A Cross-Sectional Study
}

\author{
Natasya Prameswari ${ }^{1, *,+}$, Rima Irwinda ${ }^{2}{ }^{-}$, Noroyono Wibowo ${ }^{2}$ and Yudianto Budi Saroyo ${ }^{2}$ \\ 1 Department of Obstetrics and Gynaecology, Faculty of Medicine, \\ Universitas Indonesia/Cipto-Mangunkusumo Hospital, Jakarta 10340, Indonesia \\ 2 Maternal Fetal Division, Department of Obstetrics and Gynaecology, Faculty of Medicine, \\ Universitas Indonesia/Cipto-Mangunkusumo Hospital, Jakarta 10340, Indonesia; \\ rima.irwinda@gmail.com (R.I.); wibowonoroyono@yahoo.com (N.W.); yudibs@gmail.com (Y.B.S.) \\ * Correspondence: tasyamm@hotmail.com \\ + Current address: Department of Obstetrics and Gynecology, Cipto-Mangunkusumo Hospital, Jl. Diponegoro \\ No. 71 Central, Jakarta 10340, Indonesia.
}

check for updates

Citation: Prameswari, N.; Irwinda, R.; Wibowo, N.; Saroyo, Y.B. Maternal Amino Acid Status in Severe Preeclampsia: A Cross-Sectional Study. Nutrients 2022, 14, 1019. https://doi.org/10.3390/ nu14051019

Academic Editor: Roberto Iacone

Received: 7 January 2022

Accepted: 25 February 2022

Published: 28 February 2022

Publisher's Note: MDPI stays neutral with regard to jurisdictional claims in published maps and institutional affiliations.

Copyright: (C) 2022 by the authors. Licensee MDPI, Basel, Switzerland. This article is an open access article distributed under the terms and conditions of the Creative Commons Attribution (CC BY) license (https:// creativecommons.org/licenses/by/ $4.0 /)$.
Abstract: Introduction: Preeclampsia has been one of the leading causes of maternal death in Indonesia. It is postulated that its relationship with oxidative stress may be the underlying pathology of the disease. Nutrients and amino acids have been suggested as a scavenger for oxygen-free radicals. No previous study regarding the amino acid status in preeclampsia has been conducted in women in Indonesia. Methods: This was a cross-sectional study of a total of 64 pregnant women, 30 with normal pregnancy and 34 with severe preeclampsia. Data were obtained in Cipto Mangunkusumo National Referral Hospital in Jakarta from July to December 2020. Maternal blood samples were taken during or soon after delivery. Amino acid levels were analyzed using liquid chromatographytandem mass spectrometry (LC-MS/MS). Bivariate analysis was then performed. Results: We identified 19 different levels of amino acids in this study. Four amino acids that were elevated in the preeclampsia group were phenylalanine, serine, glycine, and glutamate. Serine (331.55 vs. 287.43; $p=0.03)$, glycine (183.3 vs. $234.35, p=0.03)$, and glutamate levels $(102.23$ vs. $160.70, p=0.000)$ were higher in preeclamptic patients. While in the essential amino acids group, phenylalanine levels (71.5 vs. $85.5, p=0.023)$ were higher, and methionine levels (16.3 vs. $12.9, p=0.022)$ were lower in preeclamptic patients. Conclusions: These findings suggest that severe preeclampsia had differences in concentration of some amino acids compared to normal pregnancy. Glutamate and methionine were associated with preeclampsia. Furthermore, a more detailed study regarding amino acids in the pathomechanism of preeclampsia is suggested.

Keywords: preeclampsia; amino acid; oxidative stress

\section{Introduction}

Preeclampsia is one of the most common complications in pregnancy, as it is one of the Great Obstetrics Syndromes. Pregnancy is complicated by oxidative stress from maternal decidua and placental villus. Insufficient blood flow in the placenta can give rise to a hypoxic environment that causes ischemia reperfusion injury, marked by increasing free radicals in cells [1]. The severity of the damage depends on the cellular defense to oxidative stress [2]. Furthermore, preeclampsia is based on a complex placental pathology that is related to poor trophoblast differentiation or placental immaturity [3]. Insufficient decidualization may lead to placental hypoxia and, moreover, endothelial and vascular dysfunction manifested as preeclampsia [4].

Preeclampsia has been one of the leading causes of death in the world, as $10 \%$ of pregnancies are complicated by preeclampsia. In Indonesia, hypertension in pregnancy is reported as the second leading cause of maternal death after hemorrhage [5,6]. In Cipto 
Mangunkusumo General Hospital Jakarta, around 24.3\% of pregnant women who undergo delivery have hypertension in pregnancy every year [7].

Nutrients, such as amino acids, have a role in immunomodulatory properties and interact through common biochemical pathways. Other than being used in energy metabolism reactions and synthesis of proteins, amino acids are important for the synthesis of antioxidants, nitric oxide, histamine, and hydrogen peroxide [8]. A previous study by BahadoSingh et al. showed an increased concentration of branch-chained amino acids (BCAA) in preeclamptic patients. Dysfunctions in amino acid transport in the placenta can occur in preeclampsia and intrauterine growth restrictions. An imbalance of BCAA levels in some studies has been found to be associated with insulin resistance and preeclampsia [9].

A previous study in Jakarta, Indonesia, reported that almost all pregnant women in Jakarta had low nutrient intake in their first trimester, below their recommended dietary allowance. Most of the subjects (80.8\%) also had a low protein intake of less than $56 \mathrm{~g}$ per day [10]. Nutrients may modify certain inflammatory responses and also modulate pro-inflammatory cytokine production and action. It has also been suggested that some amino acids can directly scavenge oxygen free radicals [11]. It has been suggested that high concentrated branched-chain amino acids, such as leucine, isoleucine, and valine, induce productions of reactive oxygen species and pro-inflammatory status in peripheral blood mononuclear cells [12].

Previous studies showed higher amino acids related to preeclampsia $[13,14]$. However, there are no studies regarding amino acid status in preeclampsia and normal pregnant women in Indonesia. This study aims to evaluate the profile of the maternal serum amino acids in preeclampsia and normal pregnancy in order to be used as a basis for the prediction of preeclampsia or as supplementation to reduce the risk of preeclampsia.

\section{Materials and Methods}

\subsection{Study Participants}

This was a cross-sectional study of a total of 64 pregnant women. Out of 64 pregnant women, 30 were normal pregnancies compared to the 34 patients with severe preeclampsia. Following delivery, all participants had their blood examined, as well as given the food frequency questionnaire. Data were obtained in Cipto Mangunkusumo National Referral Hospital in Jakarta from July to December 2020. This study was approved by the Ethical Committee for Research in Humans from the Faculty of Medicine, Universitas Indonesia (KET-799/UN2.F1/ETIK/PPM.00.02/2019). All of the participants have also given their informed consent prior to their inclusion in the study.

Preeclampsia with severe features as defined by ACOG 2013, and the recently updated ACOG practice bulletin on Gestational Hypertension and Preeclampsia [15], include the criteria of blood pressure $\geq 160 / 110 \mathrm{mmHg}$, thrombocytopenia, progressive renal insufficiency, new onset cerebral or visual disturbances, and pulmonary edema. Criteria for proteinuria is expected to be $300 \mathrm{mg}$ or more in $24 \mathrm{~h}$ urine collection, protein dipstick of $2+$, or protein/creatinine ratio of $0.3 \mathrm{mg} / \mathrm{dL}$. In the absence of proteinuria, we included other criteria that match preeclampsia with severe features based on ACOG [15]. Exclusion criteria in this study include multiple pregnancy, intrauterine growth restriction, congenital anomalies, HIV-positive patients, preterm premature rupture of membrane, diabetes mellitus, infection, and autoimmune diseases.

\subsection{Nutrient Intake Assessment}

Nutrient intake from the subjects was evaluated using a semiquantitative food frequency questionnaire (FFQ) for a month. The FFQ was assessed by trained nutritionists using a food model and was converted to the Nutrisurvey program with the food database from Indonesia. The classification of the nutrient intake of protein was based on the recommended dietary allowances (RDA). 


\subsection{Sample Preparation and Amino Acid Measurements}

Maternal blood samples were taken during or soon after delivery. Samples were collected using venous puncture into $5 \mathrm{~mL}$ tubes (Vacutainer; Becton-Dickinson). The serum was then taken to the laboratory and was directly separated out from the whole blood and frozen at $-80{ }^{\circ} \mathrm{C}$ until all samples were analyzed. Amino acid levels were analyzed using liquid chromatography-tandem mass spectrometry (LC-MS/MS) 6460 Triple Quad with 1290 Infinity Binary Pump (Agilent Technologies ${ }^{\circledR}$, USA) and converted into $\mu \mathrm{M}(\mu \mathrm{mol} / \mathrm{L})$.

\subsection{Outcome Measures}

The data obtained for the characteristics of the subject include maternal age, education level, parity, gestational age, and body mass index.

The concentrations of maternal serum amino acids were then measured for both essential and non-essential amino acids. The essential amino acids examined were lysine, histidine, threonine, valine, methionine, isoleucine, leucine, phenylalanine, and arginine. Whereas the non-essential amino acids examined were aspartate, ornithine, serine, glycine, alanine, tyrosine, cystine, cysteine, and glutamate. All concentrations of the amino acid were expressed in $\mu \mathrm{M}(\mu \mathrm{mol} / \mathrm{L})$.

\subsection{Statistical Analysis}

Data were analyzed using Statistical Package for Social Sciences (SPSS) version 25.0 (IBM, United States). The numeric data were firstly checked for normal distribution using the Kolmogorov-Smirnov test, then presented as mean \pm SD if normally distributed and as median (min-max) if not normally distributed. Unpaired t-test or Mann-Whitney test were used to identify significances among groups.

In addition, receiver operating characteristics (ROC) curve analyses were used to determine cut-off values, sensitivity, and specificity of amino acid variables. To predict preeclampsia, we assessed the area under the curve (AUC). The cut-off values for parameters with high performances were determined at the highest value of sensitivity and specificity. Chi-square test was performed for bivariate analysis, followed by multivariate logistic regression for maternal age, gestational age, and pre-pregnancy BMI adjustment. Results corresponding to $p$-values $<0.05$ were considered significant.

\section{Results}

\subsection{Characteristics of Subjects}

All of the samples were included in this study. Table 1 shows the characteristics of the subjects included. There were significant differences found between the groups in terms of maternal age, parity, mode of delivery, BMI, and fetal weight. The BMI values were categorized as underweight (BMI below 18.5), normal (BMI range 18.5 to 22.9), overweight, and obese (BMI above 23). Patients with preeclampsia had higher maternal age of 31.7 (7.3) years old $(p<0.05)$, multiparity $(p<0.05)$, higher rate of cesarean section $(p<0.05)$, fetal weight lower than control $(p<0.05)$, and most BMI were $>23 \mathrm{~kg} / \mathrm{m}^{2}(p<0.05)$.

Table 1. Characteristics of subjects $(n=64)$.

\begin{tabular}{|c|c|c|c|}
\hline Variables & Control $(n=30)$ & Preeclampsia $(n=34)$ & $p$ \\
\hline Maternal age (years) & $26.9 \pm 5.9$ & $31.7 \pm 7.3$ * & 0.01 \\
\hline \multicolumn{4}{|l|}{ Education level ( $n / \%)$} \\
\hline Low education level & $23(76.7 \%)$ & $31(91.2 \%)$ & 0.111 \\
\hline High education & $7(23.3 \%)$ & $3(8.8 \%)$ & \\
\hline Gestational age at delivery (weeks) & $38.7(1.03)$ & $35.56(3.4)$ & 0.06 \\
\hline \multicolumn{4}{|l|}{ Parity $(n / \%)$} \\
\hline Nuliparity & $19(70.4 \%)$ & $8(29.6 \%)$ & 0.001 \\
\hline Multiparity & $11(29.7 \%)$ & $26(70.3 \%)$ & \\
\hline Body mass index $(n / \%)$ & & & \\
\hline
\end{tabular}


Table 1. Cont.

\begin{tabular}{ccc}
\hline Variables & Control $(\boldsymbol{n}=\mathbf{3 0 )}$ & Preeclampsia $(\boldsymbol{n}=\mathbf{3 4 )}$ \\
\hline Underweight & $4(13.3 \%)$ & $2(5.9 \%)$ \\
Normal & $11(36.7)$ & $7(20.6)$ \\
Overweight and obese & $15(50 \%)$ & $25(73.5 \%)$ \\
Mode of delivery & $22(73.3 \%)$ & $9(26.5 \%)$ \\
Vaginal delivery & $8(26.7 \%)$ & $25(73.5 \%)$ \\
Caesarean Section & $3091.67 \pm 395.4$ & $2386.91 \pm 828.1$ \\
Fetal Weight (grams) & $<0.005$ \\
\hline
\end{tabular}

Data presented as mean \pm SD. ${ }^{*}$ Significances to control $(p<0.05)$.

\subsection{Nutrient Intake within Subjects}

The daily maternal nutrient intake is shown in Table 2 . The mean daily intake of energy and carbohydrate in normal patients were higher than in preeclampsia patients. The mean protein and fat intake of preeclampsia patients were higher compared to normal patients. In protein intake, we found that most subjects in both normal and preeclampsia groups had intakes that were below the Estimated Average Requirement and RDA recommendations of $1.1 \mathrm{~g} / \mathrm{kg}$ body weight per day [16].

Table 2. Maternal nutrient intake.

\begin{tabular}{cccc}
\hline Daily Maternal Intake & Control & Preeclampsia & $p$ \\
\hline Energy (kcal) & $1809.367 \pm 707.19$ & $1792.207 \pm 759.59$ & $0.869^{*}$ \\
Carbohydrate (g) & $244.711 \pm 80.81$ & $219.100 \pm 112.28$ & $0.167^{*}$ \\
Protein (g) & $60.867 \pm 30.81$ & $130.539 \pm 334.37$ & $0.148^{*}$ \\
Fat (g) & $70.093 \pm 37.17$ & $76.582 \pm 31.12$ & $0.162^{*}$ \\
\hline
\end{tabular}

Data presented as mean \pm SD. ${ }^{*}$ Mann-Whitney Test.

\subsection{Amino Acids Levels in Normal Pregnancy and Preeclampsia}

The levels of serum amino acids, both essential and non-essential, are shown in Table 3. The preeclampsia group was found to have higher levels of most essential and non-essential amino acids.

Table 3. Amino acids levels in normal pregnancy and preeclampsia.

\begin{tabular}{cccc}
\hline Variables & Control $(N=30)$ & Preeclampsia $(N=34)$ & $p$ \\
\hline Essential Amino Acids & & $172.70(39.9)$ & 0.885 \\
Arginine & $159.33(44.5)$ & $74.02(18.7)$ & 0.330 \\
Histidine & $66.6(18.8)$ & $40.4(14.6)$ & 0.651 \\
Isoleucine & $37.2(12.7)$ & $91.05(34.8)$ & 0.726 \\
Leucine & $84.03(30.9)$ & $150.44(71-336)$ & 0.258 \\
Lycine & $139.03(62-307)$ & $12.9(5.7)$ & $0.022 *$ \\
Methionine & $16.3(5.8)$ & $85.5(26.8)$ & $0.023 *$ \\
Phenylalanine & $71.5(20.5)$ & $193.588(72.23)$ & 0.096 \\
Threonine & $166.1(55.66)$ & $111.8(36.0)$ & 0.591 \\
Valine & $111.56(38.1)$ & & \\
Aspartate & & $47.5(15.5)$ & 0.461 \\
Serine & $45.3(15.50)$ & $331.55(174-620)$ & $0.03 *$ \\
Glycine & $287.43(85-398)$ & $234.35(213.00)$ & $0.03 *$ \\
Cysteine & $183.3(59.2)$ & $6.44(1.00-45.00)$ & 0.788 \\
Alanine & $4.36(1.00-7.00)$ & $417.64(146.98)$ & 0.824 \\
Glutamate & $413.233(196-822)$ & $160.70(36-397)$ & $0.000 *$ \\
Proline & $102.23(29-183)$ & $120.88(56.1)$ & 0.483 \\
Tyrosine & $114.1(57.7)$ & $44.7(10.09)$ & 0.931 \\
Ornitine & $43.7(12.1)$ & $47.1(24.3)$ & 0.121 \\
\hline
\end{tabular}




\subsection{ROC Curve Analysis}

Amino acids that had the AUC of ROC curves $>0.65$ were considered as appropriate indicators for severe preeclampsia, and thus, included in further analyses. Essential and non-essential amino acids with AUC $<0.65$ were not taken into account.

In predicting the risk of preeclampsia, glutamate and glycine had AUCs of 0.775 and 0.658 , respectively, while methionine had an AUC of 0.672 (Figure 1). The glutamate value $\geq 109$ had $73.5 \%$ sensitivity and $66.7 \%$ specificity, the glycine value of $\geq 187.5$ had $61.8 \%$ sensitivity and $53.3 \%$ specificity, and the methionine value of $\leq 14.5$ had $67.6 \%$ sensitivity and $63.3 \%$ specificity.
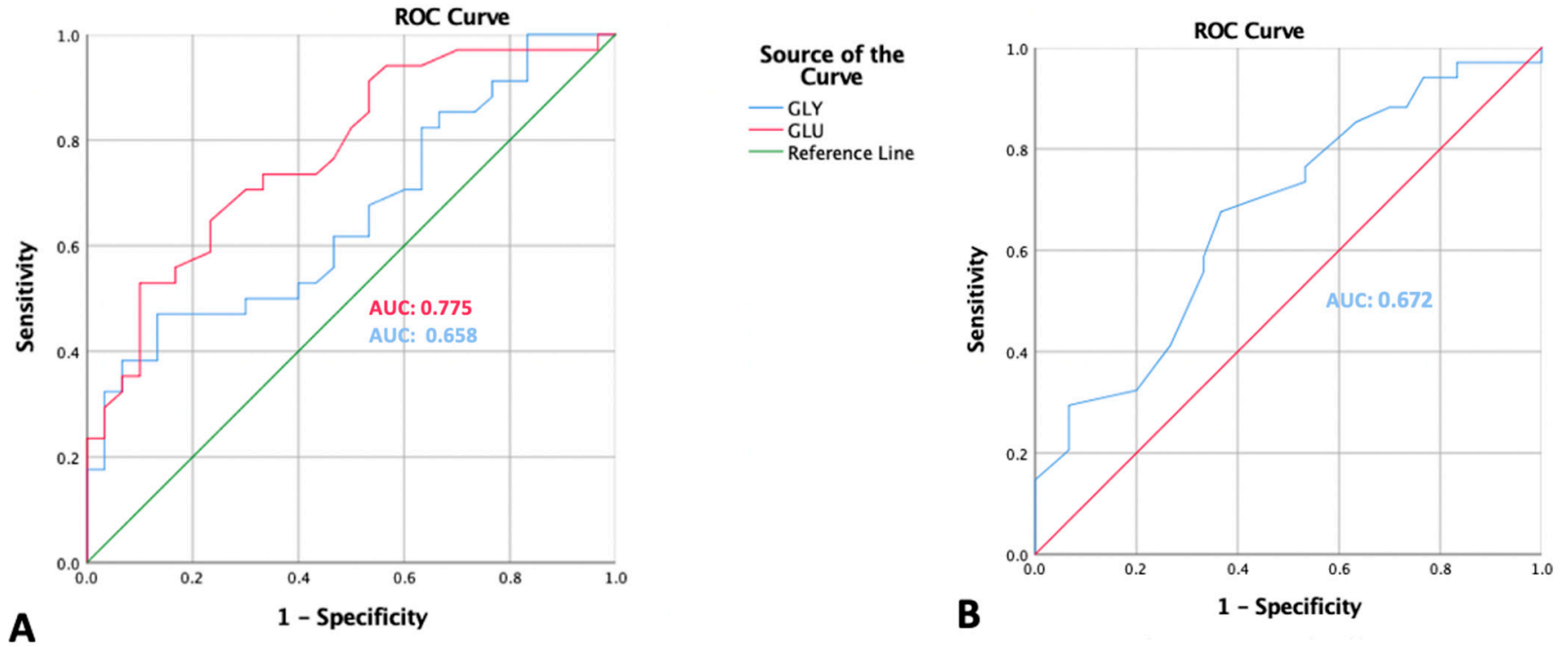

Figure 1. ROC curves of amino acids that were considered to be acceptable predictors of severe preeclampsia. (A) Glycine and glutamate. (B) Methionine.

\subsection{Bivariate and Multivariate Analysis of the Cut-Off Points}

In the bivariate analysis, only glutamate and methionine cut-off values were found to be significantly associated with severe preeclampsia $(p=0.003$ and $p=0.026)$. After adjusting for the maternal age, gestational age, and pre-pregnancy BMI, the high-risk levels of glutamate and methionine showed increased risks of severe preeclampsia with OR 5.89, 95\%CI 1.85-18.76; and OR 3.75, 95\%CI 1.24-11.3; respectively (Table 4).

Table 4. Amino acid levels and risk for preeclampsia.

\begin{tabular}{|c|c|c|c|c|c|}
\hline & $\begin{array}{c}\text { Preeclampsia } \\
n(\%)\end{array}$ & $\begin{array}{c}\text { Control } \\
n(\%)\end{array}$ & $p$ Bivariate & $\begin{array}{c}\text { OR } \\
(95 \% \mathrm{CI})\end{array}$ & $\begin{array}{l}\text { Adjusted OR } \\
(95 \% \mathrm{CI}) *\end{array}$ \\
\hline \multicolumn{6}{|l|}{ Glutamate } \\
\hline High risk $(\geq 109)$ & $25(73.5)$ & $10(33.3)$ & 0.003 & 5.55 (1.89-16.28) & $5.89(1.85-18.76)$ \\
\hline Low risk $(<109)$ & $9(26.5)$ & $20(66.7)$ & & 1.0 & 1.0 \\
\hline \multicolumn{6}{|l|}{ Glycine } \\
\hline High risk $(\geq 187.5)$ & $21(61.8)$ & $14(46.7)$ & 0.33 & $31.84(0.68-5.00)$ & \\
\hline Low risk $(<187.5)$ & $13(38.2)$ & $16(53.3)$ & & 1.0 & \\
\hline Methionine & & & & & \\
\hline High risk $(\leq 14.5)$ & $34(67.6)$ & $11(36.7)$ & 0.026 & $3.61(1.28-10.1)$ & 3.75 (1.24-11.3) \\
\hline Low risk $(>14.5)$ & $11(32.4)$ & $19(63.3)$ & & 1.0 & 1.0 \\
\hline
\end{tabular}

* Adjusted for covariates: maternal age and maternal pre-pregnancy BMI. 1.0: Reference Value.

\section{Discussion}

Our research was mostly dominated by overweight and obese participants. This finding was supported by a previous study by Ermamilia et al. [17] in Yogyakarta, Indonesia, where BMI $\geq 23 \mathrm{~kg} / \mathrm{m}^{2}$ was a predictive factor of preeclampsia. 
Higher levels of both non-essential (serine, glycine, and glutamate) and essential amino acids (phenylalanine) were detected in patients with preeclampsia compared to normal pregnancy. This finding correlates with previous findings by Liu G et al., which compared 18 amino acids in serum and cord blood samples of preeclamptic patients and normal pregnant patients [14]. The study found that glutamate and serine levels were higher in maternal blood samples of those with preeclampsia compared to normal ones. Higher nitrogen requirements of the placenta that correspond to the state of higher oxidative level in preeclampsia may give rise to the higher levels of glutamate and serine in the maternal blood [14].

Hypertension and the upregulated cycle of inducible nitric oxide (iNOS) are reported both clinically and experimentally. Glutamate induced and increased iNOS production, proteins, and also $\mathrm{Ca} 2+$. Therefore, an increase in glutamate may result in higher levels of iNOS in preeclamptic patients [18]. The higher levels of serine and glycine in preeclampsia were thought to be in connection with glycolysis defects in the placenta of preeclamptic patients. Glucose is the main source of nutrition in the placenta. Preeclampsia affects the glycolysis function, therefore causing failure in metabolism. The decreased glycolysis enzyme in the placenta causes low pyruvate and lactate productions, consequently producing less energy for the fetus $[19,20]$.

Our study showed lower methionine levels in preeclamptic patients compared to normal pregnancy. Methionine is a sulfuric amino acid that is important in protein synthesis. Some suggested that methionine can act as an immune regulatory factor, like IL-1 or insulinlike growth factor I. Methionine can protect cells from oxidative damage, which can also play a role in preeclampsia [21-24]. Methionine is also a precursor of homocysteine. Unfortunately, in our study, both folate and B12 levels were not analyzed. Some studies linked low methionine levels to B12 deficiency as cofactor methionine synthase. Folate and B12 deficiency may affect methionine, S-adenosylmethionine (SAM), and higher homocysteine due to the ineffectiveness in extracting methionine from homocysteine [19]. Methionine has been suggested to provoke transsulfuration that leads to methionine catabolism and also re-methylation through homocysteine $[25,26]$. In our study, low levels of methionine can also be caused by failure of homocysteine conversion to methionine due to low B12 levels.

A previous study found that $74.8 \%$ of the first trimester pregnant women in Jakarta, Indonesia had low daily maternal folate intake but high maternal folate in serum [10]. Methylenetetrahydrofolate reductase (MTHFR) is a key enzyme in regulating folate balance and homocysteine conversion to methionine [27]. MTHFR and homocysteine levels are associated with preeclampsia, since previous studies have found the correlation between MTHFR polymorphism and preeclampsia $[27,28]$. In this study, homocysteine, vitamin B12, and MTHFR were not evaluated; therefore, future studies should evaluate the role of MTHFR enzymes.

Our findings suggest that severe preeclampsia had significant differences in the concentrations of some amino acids compared to normal pregnancy. Nevertheless, our study did not give a clear view of the causal relationship between amino acids and preeclampsia since our samples were limited to only maternal serum. The study by Liu et al. revealed that amino acid levels differ in maternal and cord blood of preeclampsia patients. It might show that the different levels of amino acids have an influence on fetal health related to fatty acid oxidation [14]. Preeclampsia is a complicated process that can result in abnormal changes in the metabolism of both fetal and maternal serum that can result in adverse consequences. Abnormalities in the amino acid pathways have not yet been fully understood until now.

Previous studies showed that fasting state is related to the concentration of amino acids [29]. In our study, all of the serum amino acid levels were taken without the patients fasting. Therefore, a more elaborate study that defines whether the serum is taken during fasting or postprandial state is suggested. We also suggest a more detailed study regarding the role of amino acids in the pathomechanism of preeclampsia. However, this is the first study in Indonesia that investigated the amino acid profile in maternal serum of preeclamptic patients. 


\section{Conclusions}

Glutamate, serine, glycine, and phenylalanine amino acid levels were elevated in the maternal serum of preeclampsia patients. Glutamate increases the risk of preeclampsia by 5.5 times, whereas low methionine levels can increase the risk of preeclampsia by 3.6 times. We suggested a more detailed study regarding maternal intake, maternal serum, cord blood, placental amino acid levels, and their correlations with oxidative stress and inflammation in preeclampsia patients.

Author Contributions: R.I., N.P. and N.W. designed and conducted the study. R.I. and N.P. collected and analyzed the data. N.P. wrote the manuscript, R.I., N.W., and Y.B.S. revised and are responsible for all the content. All authors have read and agreed to the published version of the manuscript.

Funding: This research was funded by 2019 PITTA (Publikasi Internasional Terindeks untuk Tugas Akhir Mahasiswa Universitas Indonesia) Grant.

Institutional Review Board Statement: The study was conducted according to the guidelines of the Declaration of Helsinki, and was approved by the Ethical Committee for Research in Humans from the Faculty of Medicine, Universitas Indonesia (KET-799/UN2.F1/ETIK/PPM.00.02/2019).

Informed Consent Statement: Informed consent was obtained from all subjects involved in the study.

Data Availability Statement: The data used in this study can be requested from the corresponding author upon reasonable request.

Acknowledgments: Authors would also like to express gratitude to all participating patients and medical staff on the Department of Obstetrics and Gynecology, Faculty of Medicine Universitas Indonesia-Cipto Mangunkusumo National General Hospital. All authors would also like to thank Rabbania Hiksas and Angga Wiratama Lokeswara for their assistance in language and statistics measurements.

Conflicts of Interest: Authors declare that there is no conflict of interest in this study.

\section{References}

1. Di Renzo, G.C. The Great Obstetrical Syndromes. J. Matern. Neonatal Med. 2009, 22, 633-635. [CrossRef]

2. Bahinipati, J. Ischemia Modified Albumin as a Marker of Oxidative Stress in Normal Pregnancy. J. Clin. Diagn. Res. 2016. Available online: http: / /jcdr.net/article_fulltext.asp?issn=0973-709x\&year=2016\&volume=10\&issue=9\&page=BC15\&issn=09 73-709x\&id=8454 (accessed on 28 February 2021). [CrossRef]

3. Fantone, S.; Mazzucchelli, R.; Giannubilo, S.R.; Ciavattini, A.; Marzioni, D.; Tossetta, G. AT-rich interactive domain 1A protein expression in normal and pathological pregnancies complicated by preeclampsia. Histochem. Cell Biol. 2020, 154, 339-346. [CrossRef] [PubMed]

4. Opichka, M.A.; Rappelt, M.W.; Gutterman, D.D.; Grobe, J.L.; McIntosh, J.J. Vascular Dysfunction in Preeclampsia. Cells 2021, 10, 3055. [CrossRef] [PubMed]

5. Wallis, A.B.; Saftlas, A.F.; Hsia, J.; Atrash, H.K. Secular Trends in the Rates of Preeclampsia, Eclampsia, and Gestational Hypertension, United States, 1987-2004. Am. J. Hypertens. 2008, 21, 521-526. [CrossRef] [PubMed]

6. Jeyabalan, A. Epidemiology of preeclampsia: Impact of obesity. Nutr. Rev. 2013, 71, S18-S25. [CrossRef]

7. Al Fattah, A.N.; Putri, A.K.; Prakoso, R.; Irwinda, R.; Wibowo, N.; Santoso, B.I. Delivery Outcome Among Pregnant Women with Hypertension. J. Hypertens. 2015, 33, e13. [CrossRef]

8. Li, P.; Yin, Y.-L.; Li, D.; Kim, S.W.; Wu, G. Amino acids and immune function. Br. J. Nutr. 2007, 98, 237-252. [CrossRef]

9. Bahado-Singh, R.O.; Syngelaki, A.; Mandal, R.; Graham, S.F.; Akolekar, R.; Han, B.; Bjondahl, T.C.; Dong, E.; Bauer, S.; AlpaySavasan, Z.; et al. Metabolomic determination of pathogenesis of late-onset preeclampsia. J. Matern. Neonatal Med. 2016, 30, 658-664. [CrossRef]

10. Wibowo, N.; Bardosono, S.; Irwinda, R.; Syafitri, I.; Putri, A.S.; Prameswari, N. Assesment of the nutrient intake an micronutrient status in the first trimester of pregnant women in Jakarta. Med. J. Indones. 2017, 26, 109-115. [CrossRef]

11. Xu, H.; Shatenstein, B.; Luo, Z.C.; Wei, S.; Fraser, W.N. Role of nutrition in the risk of preeclampsia. Nutr. Rev. 2009, 67, 639-657. [CrossRef] [PubMed]

12. Zhenyukh, O.; Civantos, E.; Ruiz-Ortega, M.; Sánchez, M.S.; Vázquez, C.; Peiró, C.; Egido, J.; Mas, S. High concentration of branched-chain amino acids promotes oxidative stress, inflammation and migration of human peripheral blood mononuclear cells via mTORC1 activation. Free Radic. Biol. Med. 2017, 104, 165-177. [CrossRef]

13. Evans, R.W.; Powers, R.W.; Ness, R.B.; Cropcho, L.J.; Daftary, A.R.; Harger, G.F.; Vergona, R.; Finegold, D.N. Maternal and fetal amino acid concentrations and fetal outcomes during pre-eclampsia. Reproduction 2003, 125, 785-790. [CrossRef] [PubMed] 
14. Liu, G.; Deng, W.; Cui, W.; Xie, Q.; Zhao, G.; Wu, X.; Dai, L.; Chen, D.; Yu, B. Analysis of amino acid and acyl carnitine profiles in maternal and fetal serum from preeclampsia patients. J. Matern. Neonatal Med. 2019, 33, 2743-2750. [CrossRef] [PubMed]

15. ACOG. Practice Bulletin. Gestational Hypertension and Preeclampsia. Available online: https://pubmed.ncbi.nlm.nih.gov/3244 3079/ (accessed on 24 February 2022).

16. Elango, R.; Ball, R. Protein and Amino Acid Requirements during Pregnancy. Adv. Nutr. Int. Rev. J. 2016, 7, 839S-844S. [CrossRef]

17. Ermamilia, A.; Yonika, L.; Aulia, B.; Ganap, E.P. High Prepregnancy Body Mass Index and Excessive Gestational Weight Gain as Obesity-Related Risk Factors of Preeclampsia. Top. Clin. Nutr. 2020, 35, 299-308. [CrossRef]

18. Amaral, L.M.; Pinheiro, L.C.; Guimaraes, D.A.; Palei, A.C.T.; Sertorio, J.T.; Portella, R.L.; Tanus-Santos, J.E. Anthypertensive effects of inducivle nitric oxide synthase inhibition in experimental pre-eclampsia. J. Cell. Mol. Med. 2013, 17, 1300-1307.

19. Troen, A.M.; Lutgens, E.; Smith, D.E.; Rosenberg, I.H.; Selhub, J. The atherogenic effect of excess methionine intake. Proc. Natl. Acad. Sci. USA 2003, 100, 15089-15094. [CrossRef]

20. Aye, I.L.M.H.; Aiken, C.E.; Charnock-Jones, D.S.; Smith, G.C.S. Placental energy metabolism in health and disease-Significance of development and implications for preeclampsia, American. J. Obstet. Gynecol. 2020, 226 (Suppl. 2), S928-S944. [CrossRef]

21. Luo, S.; Levine, R.L. Methionine in proteins defends against oxidative stress. FASEB J. 2008, 23, 464-472. [CrossRef] [PubMed]

22. Ruan, T.; Li, L.; Peng, X.; Wu, B. Effects of Methionine on the Immune Function in Animals. Health 2017, 09, 857-869. [CrossRef]

23. Kantorow, M.; Hawse, J.R.; Cowell, T.L.; Benhamed, S.; Pizarro, G.O.; Reddy, V.N.; Hejtmancik, J.F. Methionine sulfoxide reductase A is important for lens cell viability and resistance to oxidative stress. Proc. Natl. Acad. Sci. USA 2004, 101, 9654-9659. [CrossRef] [PubMed]

24. Sreekumar, P.G.; Kannan, R.; Yaung, J.; Spee, C.K.; Ryan, S.J.; Hinton, D.R. Protection from oxidative stress by methionine sulfoxide reductases in RPE cells. Biochem. Biophys. Res. Commun. 2005, 334, 245-253. [CrossRef] [PubMed]

25. Hosseini, S.A.; Zaghari, M.; Lotfollahian, H.; Shivazad, M.; Moravaj, H. Reevaluation of Methionine Requirement Based on Performance and Immune Responses in Broiler Breeder Hens. J. Poult. Sci. 2012, 49, 26-33. [CrossRef]

26. Romano, A.; Serviddio, G.; Calcagnini, S.; Villani, R.; Giudetti, A.M.; Cassano, T.; Gaetani, S. Linking lipid peroxidation and neuropsychiatric disorders: Focus on 4-hydroxy-2-nonenal. Free Radic. Biol. Med. 2017, 111, 281-293. [CrossRef]

27. Salimi, S.; Saravani, M.; Yaghmaei, M.; Fazlali, Z.; Mokhtari, M.; Naghavi, A.; Mashhadi, F.F. The early-onset preeclampsia is associated with MTHFR and FVL polymorphisms. Arch. Gynecol. Obstet. 2014, 291, 1303-1312. [CrossRef]

28. Mazloomi, S.; Alimohammadi, S.; Khodadadi, I.; Ghiasvand, T.; Shafiee, G. Evaluation of methylenetetrahydrofolate reductase (MTHFR) activity and the levels of homocysteine and malondialdehyde (MDA) in the serum of women with preeclampsia. Clin. Exp. Hypertens. 2020, 42, 590-594. [CrossRef]

29. Lee, S.-G.; Yim, Y.S.; Lee, Y.-H.; Lee, B.-W.; Kim, H.-S.; Kim, K.-S.; Kim, J.-H. Fasting serum amino acids concentration is associated with insulin resistance and pro-inflammatory cytokines. Diabetes Res. Clin. Pract. 2018, 140, 107-117. [CrossRef] 